\title{
MORTES PREMATURAS E CONFLITO ARMADO PELO DOMÍNIO DAS FAVELAS NO RIO DE JANEIRO*
}

\section{Alba Zaluar Christovam Barcellos}

\section{Introdução}

A discussão internacional sobre os determinantes das mortes por agressão nos estudos quantitativos tem se resumido a algumas teorias que se baseiam ora em variáveis individuais, que recuperam os perfis socioeconômicos das vítimas, ora em variáveis familiares, especialmente as que podem indicar "desorganização familiar", ora em variáveis ecológicas, que tentam correlacionar características das vizinhanças onde viviam as vítimas com as taxas locais de homicídios. Entre as primeiras, destacam-se a renda, a escolaridade e o gênero; entre

* Agradecemos a pesquisadora Renata Gracie pela organização dos dados espaciais e elaboração de mapas. Agradecemos também o financiamento dos projetos E 26/ 110.302/10; 101.516/2010 (Faperj); 482431/2010-5 (CNPq) (AZ) e 304639/2010-9 (CB).

Artigo recebido em 22/03/2012

Aprovado em 28/09/2012 as segundas, a composição da família ou do grupo doméstico, a ausência de figura paterna, a gravidez na adolescência; entre as terceiras, a desigualdade de renda, a estrutura populacional, a densidade demográfica e a taxa de desemprego na localidade. De acordo com essas teorias, as vítimas morariam em bairros superpovoados, etnicamente heterogêneos e com altas taxas de desemprego; bairros cuja população é de renda e escolaridade mais baixa; viriam de famílias chefiadas por mulheres e com gravidez na adolescência. São escassos, entretanto, estudos que tomem conjuntamente tais determinantes, procurando entender a interação entre eles. Poucos estudos consideram as configurações geopolíticas locais dadas pela atuação de grupos ou de governo (Rojas et al., 2005). De qualquer modo, além do uso de variáveis socioeconômicas e individuais agregadas, a compreensão de fatores relacionados com o espaço urbano tornou-se parte da investigação criminológica. 
Assim, a análise ecológica das distribuições dos delitos criminais em centros urbanos nos conduz a questôes de natureza prática e teórica. $\mathrm{O}$ modelo ecológico de geração do crime busca a compreensão da natureza multifacetada ou complexa da violência no sentido de identificar fatores que influenciam o comportamento, aumentando ou diminuindo o risco de cometer ou de ser vítima de violência nas mesmas condiçôes socioeconômicas. Como muitos dos indicadores das variáveis são dificilmente mensuráveis, as respostas a essas questões tornam a pesquisa de campo etnográfica imprescindível, com a necessária substituição de alguns conceitos, como, por exemplo, de "comportamento" para práticas sociais ou "etos", habitus, "disposições" (Bourdieu, 1972; Elias e Dunning, 1993) e illusio (Bourdieu e Wacquant, 1992, pp. 115-121). Para acompanhar os complexos processos que provocam e consolidam tais práticas sociais, a pesquisa deve ser feita segundo o método dos casos desdobrados, que permite vincular o local às demais esferas da vida social, além de impor uma abordagem histórica ou de desenvolvimento ao longo do tempo e uma pluralidade de fontes de dados (Gluckman, 1961; Burawoy, 1998, 2000). Por exemplo, localidades caracterizadas pela pobreza e desigualdade são diferentemente marcadas também pela capacidade de associação entre os vizinhos e pela escassez de órgãos e serviços públicos, quando comparados com as regióes abastadas, sugerindo que o nó estaria também na articulação entre poder público e a organização local.

O Rio de Janeiro tem se destacado como lócus da violência urbana no Brasil, com uma das maiores taxas de homicídio entre as capitais e sediando importantes pesquisas sobre violência. No entanto, este cenário tem se alterado rapidamente nos últimos anos. São percebidas mudanças na estratégia de governo de controle de grupos criminosos e a expansão da atuação de milícias. Tais mudanças possuem uma lógica espacial, já que visam à ocupação de territórios e, por isso, têm consequências diferenciadas sobre a violência na cidade, atingindo alguns grupos sociais e bairros com maior intensidade.

O objetivo deste artigo é discutir por que algumas localidades, dentro da divisão de Áreas Administrativas (AP) do Rio de Janeiro, têm altas taxas de homicídios, levando em consideração não só a distribuição espacial dos locais com concentração de mortes por agressão, interpretados à luz do que já foi apurado por pesquisas de vitimização e pesquisas etnográficas anteriores, mas também os conflitos armados pelo domínio de favelas da cidade. Essa discussão se deu sob a perspectiva da complexidade e da interdisciplinaridade, garantida pela cooperação entre diferentes metodologias que serviram para complementar os dados obtidos pelo levantamento dos domínios existentes nas favelas, combinando a objetividade da ciência positiva dos inquéritos com a subjetividade da ciência reflexiva (Burawoy, 1998, 2000; Bourdieu e Wacquant, 1992).

\section{Metodologias}

Na pesquisa domiciliar de vitimização de 20052006, sobre o universo da população a partir de 15 anos na cidade do Rio de Janeiro, foi calculada uma amostra aleatória nos três estágios da pesquisa que totalizou 4 mil pessoas. Primeiro, foram sorteados duzentos setores censitários categorizados segundo as características socioeconômicas de cada um, para que nenhum setor da população deixasse de estar representado. Segundo, em cada setor, depois de ter todos os seus domicílios arrolados pelos pesquisadores, vinte domicílios foram escolhidos pelo critério de pulo, que depende do número de domicílios arrolados em cada um deles. Terceiro, uma pessoa de 15 anos ou mais em cada domicílio foi escolhida, de acordo com 32 tabelas montadas para assegurar a representatividade de cada sexo e grupo de idade. Em 2007, na pesquisa repetida apenas nas favelas da cidade, o mesmo procedimento foi adotado com menos setores censitários, pois a amostra foi de 660 pessoas. Em ambas as pesquisas, o instrumento adotado - questionário - foi apresentado à pessoa escolhida junto com um texto em que se garantiu total anonimato. A cooperação foi voluntária e resultou em dois bancos de dados montados em SPSS, um da cidade, outro apenas de favelas. Seu objetivo, como acontece na sociologia positiva, era homogeneizar as experiências de vitimização dos inquiridos a fim de mensurá-las segundo agregados socioeconômicos. Devido ao 
tamanho da amostra, só foi possível fazer comparações e correlações entre algumas variáveis tomando as Áreas de Planejamento (AP) em que a cidade está dividida administrativamente. As APs são formadas por conjuntos de bairros e foi usada neste trabalho como unidade espacial de agregação, para a construção de gráficos e mapas,

O levantamento das favelas dominadas por facções do tráfico ou por milícias foi realizado pela mesma equipe da pesquisa de vitimização, habituada a percorrer o extenso território da cidade, em trabalho de campo com entrevistas a informantes-chave sobre a organização que dominava a favela. A lista das 965 favelas existentes no município do Rio de Janeiro em 2008 foi fornecida pelo Instituto Pereira Passos (IPP). Cada uma delas recebeu a visita da equipe de campo para, por meio de conversas com os informantes-chaves, identificar quais eram os domínios em 2010 e quais tinham sido em anos anteriores até 2005. A única pergunta nesse levantamento foi, portanto, que grupo exercia o domínio sobre a favela em que moravam as pessoas inquiridas. Após isso, a informação foi incorporada ao banco de dados das favelas usando o programa Excel. A relação prévia de confiança entre os pesquisadores e os pesquisados, por conta da realização de inúmeras pesquisas, garantiu a confiabilidade das informações. ${ }^{1}$

A análise geográfica da disputa pelo domínio das favelas exigiu que se mapeasse todas as favelas segundo seus respectivos domínios. Os mapas digitais de favelas, bairros e APs da cidade foram cedidos pelo IPP e incorporados ao Sistema de Informações Geográficas (SIG). O dados oficiais do IPP sobre favelas foram compatibilizados com a informação obtida no campo comparando-se os endereços e os nomes oficiais e outros nomes de favelas, que nem sempre são coincidentes.

Os registros de morte por agressão entre os anos de 2006 e 2009 foram georreferenciados segundo o local de ocorrência da agressão anotado pela polícia no momento da investigação ou do encontro do corpo da vítima. De um total de 9.895 registros, foram localizados 9.148 endereços, ou seja, cerca de $8 \%$ não foram georreferenciados em razão do mau preenchimento do endereço.

Foram utilizadas técnicas de geoprocessamento para a organização e análise dos dados sobre favelas e homicídios. Os Sistemas de Informações Geográficas (SIG) permitem armazenar uma grande quantidade de dados, estruturando-os e integrando-os adequadamente para que possam ser realizadas análises estatísticas que considerem a posição geográfica em polígonos para representar as favelas e pontos para localizar as mortes por agressão (Vine et al.,1997).

A análise espacial baseou-se em técnicas exploratórias: mapas de localização de pontos, de padrão e de superfícies de densidade de pontos. Na construção dos mapas de superfície foi utilizado estimador de densidade Kernel, visando à identificação visual das áreas "quentes", isto é, que apresentam maior densidade local dos eventos sobre a área estudada e obtendo-se uma "superfície de risco" para sua ocorrência, isto é, a estimativa de uma variável contínua no espaço, independente dos limites político-administrativos (Bailey e Gastrell, 1995).

Por fim, as pesquisas etnográficas, realizadas ao longo de trinta anos e já publicadas (Zaluar, 1994, 2004), foram usadas para entender as estruturas simbólicas, as subjetividades, as redes de relaçôes e as dinâmicas históricas na perspectiva do método de casos desdobrados que exige entrevistar os atores importantes nos locais onde são vividas as situações sociais de conflito, no caso, jovens atraídos por quadrilhas, moradores, líderes comunitários e policiais. Essas pesquisas foram realizadas na perspectiva da sociologia reflexiva (Burawoy, 1998, 2000; Bourdieu e Wacquant, 1992). Nelas, a observação participante, a observação sem participação, as entrevistas semiestruturadas e os grupos focais foram largamente empregados, sempre com a garantia do anonimato dos entrevistados, após explicação sobre os objetivos da pesquisa e a aceitação voluntária dos participantes. Ao contrário da ciência positiva, nestas pesquisas procuram-se o contexto situacional e o entendimento que os sujeitos da pesquisa têm das situações vividas. Começa com o diálogo entre pesquisador e os múltiplos atores da situação em foco para expandir o entendimento das conexões entre as situações locais e os processos extralocais, entre o poder local e as forças societárias ali presentes, portanto movendo-se entre o micro e o macro, entre o único e o geral, entre o observado hoje e o processo histórico que as antecedeu. 


\section{Pesquisas etnográficas publicadas}

Sob a perspectiva da complexidade, é possível afirmar que as variáveis pessoais e familiares indicadoras da pobreza não explicam totalmente a arregimentação de jovens para as atividades do tráfico, onde ficam vulneráveis à morte prematura por agressão por armas de fogo. Mas não se pode negar que a pobreza, conjugada às falhas do Estado na criação de possibilidades de ascensão social ou aquisição de respeito, às quais se deve adicionar o hedonismo de novas culturas jovens, estimule a adesão de jovens ao uso de drogas ilícitas e às práticas violentas do tráfico, aumentando a exposição aos riscos. Também a urbanização acelerada, além de não garantir emprego para todos os migrantes e, depois, para os filhos destes que não adquirem o nível de escolaridade suficiente para sair da faixa de alto desemprego entre jovens (Swartzman e Cossío, 2006), não permite que as práticas sociais urbanas da tolerância e civilidade sejam assimiladas entre os novos habitantes das cidades (Zaluar, 1998).

O próprio crescimento das favelas na cidade tem que ser considerado em articulação com a migração desordenada e a informalidade dos negócios nas "aglomerações subnormais", assim definidas pelo IBGE, que se tornaram um novo mercado para muitos bens, inclusive os imobiliários. A falta de controle legal sobre tais negócios, a dificuldade de acesso ao sistema de justiça pelos seus habitantes, assim como os obstáculos urbanos criados pela construção densa de tais aglomerados fizeram das favelas alvos do crime organizado ou "santuários", alguns inexpugnáveis, para traficantes armados do varejo das drogas. Por conta da rivalidade letal entre os comandos do tráfico que se organizaram desde a prisão foi necessário dominar territorialmente as favelas, o que começou a ocorrer no final dos anos de 1980. Disso decorreu uma corrida armamentista entre os comandos, como forma de amedrontar os adversários e inibir invasōes e beligerâncias (Zaluar, 1994, 2004).

Mas há que considerar outras dimensões que ultrapassam os limites da cidade e do país. O surgimento e o crescimento do crime organizado ou crime-negócio devem ser entendidos no contexto de grandes mudanças macrossociais no mundo e, em particular, no Brasil. Em cenário de redução do desenvolvimento econômico, ou mesmo de desindustrialização como acontece nas maiores cidades brasileiras, mais pessoas podem vir a ser atraídas para o arriscado tráfico de drogas, que se torna mais viável e lucrativo em algumas áreas da cidade, onde a logística de distribuição de armas e drogas é mais transitável e rápida. $\mathrm{O}$ crime organizado é, de fato, aquele que melhor se entende pela teoria da escolha racional (Newman, Clarke e Shoham, 1997), visto que tem o objetivo claro de manter aquelas atividades que negociam bens e serviços maximizando os ganhos e minimizando as perdas. A necessária organização de ações que buscam obstruir a detecção e a acusação judicial, seguindo o jogo sujo e violento das atividades fora e contra a lei, só pode ser montada onde se conta com a cumplicidade de encarregados do combate ao crime (Luppo, 2002). Sem considerar as estratégias eficazes de corrupção dos agentes da lei, não seria possível compreender a facilidade com que armas e drogas chegam às favelas e a bairros populares do Rio de Janeiro (Zaluar, 1994), nem como as mercadorias roubadas - automóveis, caminhōes, joias, eletrodomésticos -, usadas como valor de troca na compra de drogas ilegais, chegam com facilidade ao seu destino em outros estados e países vizinhos que precisam de escoadouros desimpedidos (Beato, 1998; Geffray, 2002). Os mecanismos e os fluxos institucionais do sistema de Justiça, ineficaz no combate ao crime organizado, criam ao mesmo tempo ilhas de impunidade e focos de cumplicidade para garantir a continuidade do negócio, diminuindo as perdas dos envolvidos nele.

O comércio de drogas tornou-se sinônimo de guerra em muitos municípios do Brasil, mas com diferenças regionais entre cidades e entre bairros na mesma cidade. No Rio de Janeiro, mesmo que não completamente coordenado por uma hierarquia mafiosa, o comércio de drogas tem um arranjo eficaz. As quadrilhas ou comandos conciliam os dispositivos de uma rede geograficamente definida, que inclui pontos centrais ou de difusão, com outros que se estabelecem na base da reciprocidade horizontal, segundo a qual quando uma favela fica sem drogas ou armas podem-se obtê-las de favelas "amigas", sob o domínio da mesma facção (Zaluar, 2001). Além do mais, teve início uma corrida ar- 
mamentista com o objetivo de dissuadir os rivais de entrarem em guerra devido ao número de soldados ou de armas exibido pela quadrilha ou comando.

Apesar disso, traficantes pertencentes a comandos inimigos ou policiais versus traficantes engajam-se em conflitos armados constantemente, o que passa a ser percebido como uma guerra. Nela, os "soldados do tráfico" ou "falcôes" formam um "bonde" que responderá ao ataque de outro "bonde" constituído da mesma maneira. Por isso, os vizinhos não têm permissão de cruzar as fronteiras entre as favelas rivais. Muitos homens jovens foram mortos apenas porque passaram de um setor a outro comandado pelas redes beligerantes do tráfico (Zaluar, 2001; Cecchetto, 2004). Nessas arenas de conflito, desenvolve-se, então, um estilo de masculinidade denominado etos guerreiro (Zaluar, 2001; Cecchetto, 2004; Monteiro, 2009) semelhante ao que acontece em gangues norte-americanas, nas maras salvadorenhas e outras formações difundidas pela globalização da cultura e do crime (Elias e Dunning, 1993; Zaluar, 2004; Cecchetto, 2004; Monteiro, 2009).

No contexto social marcado pelo conflito armado e de "muito dinheiro no bolso", propiciado pelo tráfico de drogas, surge outro estilo de masculinidade interacional e conjuntural, definido como hipermasculinidade exibicionista, exagerada, uma "exibição espetacular de protesto masculino" (Connel, 1987). Trata-se de um meio de organizar as práticas sociais socialmente valorizadas ou aceitas em um meio "marginal", ou seja, fora da masculinidade hegemônica e do centro de poder. São homens que não puderam construir a identidade masculina, como os tradicionais operários, pelo trabalho, pela educação, pelas propriedades e pelo consumo de bens duráveis, coisas que um emprego de trabalho manual permitia até meados do século passado. No contexto marginal, por suas ações exibicionistas de força física e gastos orgiásticos, esses homens tornam-se ameaça para as vizinhanças e as pessoas que os cercam (Holland e Scourfield, 2000). De uma dinâmica da economia informal transfigurada em ilegal, cristaliza-se a "cultura de rua” violenta. Segundo Bourgois (1996), que estudou esta cultura nos Estados Unidos, os milhões de dólares dos negócios na rua, não bem estimados, tornaram-se "a estratégia masculina mais visível publicamente" ou uma "alternativa para a dignidade pessoal autônoma”.

Não se trata, pois, de guerra civil entre pessoas de classes sociais diferentes, nem de uma guerra entre policiais e bandidos. A guerra convencional exige um código de normas relativo a prisioneiros e à população civil, inexistente nesses conflitos sem controle institucional (Kaldor, 1999). Estes podem ser mais bem entendidos como moleculares, por estarem localizados em múltiplos territórios que escapam ao controle do Estado de Direito; poderiam se encaixar também na definição de guerra de quarta geração, que envolve tanto os conflitos étnicos e religiosos como os do crime organizado, uma vez que arrastam consigo jovens e crianças e usam armas ditas leves (Dowdney, 2004, 2008; Kaldor, 1999).

As favelas e seus arredores tornaram-se, assim, parte das "áreas quentes" da ecologia do perigo, socializando jovens vulneráveis no desejo e no manejo das armas de fogo, elementos-chave da nova "cultura de rua", e causando sua morte prematura (Iyer e Monteiro, 2004).

Os bem equipados traficantes, com um impressionante estoque de armas e munições - denominado "paiol" - apontam para o paradoxo do monopólio legítimo da violência no Brasil e para a logística até então inquebrantável, que aporta armas e munições continuamente às quadrilhas atuantes no varejo das favelas do Rio de Janeiro. Além de treiná-los para o combate, policiais e militares corruptos, auxiliados por contrabandistas, levam armas sofisticadas, importadas, ou de uso exclusivo das Forças Armadas brasileiras às quadrilhas, o que torna factível um estado de combate armado permanente pelo controle dos pontos de venda e dos territórios urbanos; armas essas que serão usadas para atingir justamente policiais que reprimem as atividades ilegais.

O porte de armas de fogo, por sua vez, se explica pelo contexto sociocultural dos pequenos grupos a que pertencem os jovens que seguem os valores e as práticas desta cultura de rua. Outros estudos, sobretudo nos Estados Unidos, apontam o grupo de pares como o maior preditivo de delinquência entre homens jovens, especialmente os crimes violentos mais graves e o hábito de portar armas 
(Myers et al.,1997). ${ }^{2}$ A família poderia influir direta ou indiretamente, mas é a rede de relaçōes do jovem com outros jovens de sua idade ou de idade superior que aparece como o fator mais importante para se entender seu comportamento. Outros estudos afirmam que, entre os preditores da violência entre jovens, "carregar arma" e "repetência escolar" são aspectos relevantes (Saner et al., 1996; Resnick et al., 2004). Mais do que uma inclinação natural dos homens jovens pobres à violência, o que explica o aumento da taxa de homicídios nos locais onde vivem é a alta concentração de armas nestes locais. É isso que cria o que o criminologista Jeffrey Fagan (2005) chamou ecology ofdanger. ${ }^{3}$ Nas várias pesquisas de campo realizadas pela equipe do Nupevi no Rio de Janeiro, sempre foi assinalada, desde 1980, a facilidade e a quantidade de armas disponíveis para os jovens moradores das favelas tidas como perigosas.

\section{Pesquisa de vitimização}

Centro (AP 1) e subúrbios (AP 3) são as áreas mais populosas ou de maior densidade demográfica e as mais afetadas pela desindustrialização, segundo os dados da pesquisa domiciliar de vitimização realizada em 2005-2006 em toda a cidade e a realizada apenas em favelas em 2007 (Zaluar et al., 2007). Não são, todavia, as piores áreas em se tratando de serviços públicos. Estes se encontram bem distribuídos na cidade, com apenas em torno de 1\% dos domicílios sem rede geral de água e eletricidade, o que é confirmado em outra pesquisa baseada nos dados da PNAD (Cardoso, 2008).

No entanto, quando se focaliza outros recursos e serviços públicos, os contrastes aparecem com nitidez. O que mais chama atenção na pesquisa é o estilo de policiamento, mais violento e corrupto nos bairros e favelas onde predominam famílias abaixo da linha de pobreza, escolaridade baixa e desemprego entre jovens. As pesquisas de vitimização revelam que a Polícia Militar, que faz o policiamento ostensivo, está muito mais ausente em bairros e favelas onde moram os mais pobres $\mathrm{da}$ cidade. Ao mesmo tempo, ela é muito mais violenta nas áreas que estão sob o controle de quadrilhas de traficantes, onde faz incursões esporádicas, especialmente nas favelas que abundam nos subúrbios (AP 3), como Madureira ou Ramos. Nas favelas, os policiais atiram dez vezes mais do que nas áreas regulares do asfalto e agridem duas vezes mais os moradores. No entanto, a proporção de moradores que viram policiais atirando em suas vizinhanças é vinte vezes menor na Tijuca (AP 2), com numerosa população de classe média, mas com favelas conhecidas como santuários do tráfico. Cerca de 0,5\% dos entrevistados presenciaram ações violentas da polícia na Tijuca, enquanto nos subúrbios próximos (AP 3.1), chegam a 11\% dos entrevistados.

Em anos recentes observa-se uma mudança significativa dos domínios em favelas, o que tem produzido uma alteração na estratégia policial de controle de territórios, bem como um rearranjo espacial dos domínios de facções criminosas. Essas mudanças têm raízes na crise interna do tráfico e na expansão das "milícias" na cidade, o que foi captado pelas pesquisas de vitimização e de domínio territorial de grupos armados, realizadas neste estudo.

A dificuldade em garantir a segurança da população estava criando novos problemas que ameaçavam paralisar a Polícia. Sem contar com o controle informal dos vizinhos que se enfraqueceu no processo de militarização dos traficantes, nem com a mediação de conflitos entre estes últimos sempre disputando o controle dos pontos de venda e de poder local, a Polícia se limitava até 2008 a entrar em locais já conflagrados pelo conflito armado, por meio de invasóes marcadas pela violência e pelo caráter provisório. Em um círculo vicioso infindável, esta situação só fazia reforçar práticas policiais baseadas no seu poder de fogo e na perspectiva das ações repressivas da "guerra contra os inimigos internos" ou da "caça aos bandidos", estabelecidas nas últimas décadas. A ideia da guerra contra outro poder armado "paralelo", com alta capacidade de corromper, dificultava enormemente a adesão às normas legais que deveriam orientar a ação policial, já dificultada pelo alto poder de corrupção dos ricos traficantes de drogas ilegais. Além disso, a imagem da Polícia Militar como violenta e corrupta atingiu percentuais incrivelmente altos entre os jovens favelados, especialmente as mulheres: mais de 70\% deles concordava que a PM era violenta e corrupta, 
chegando a $92 \%$ das faveladas entre 15 e 19 anos. Esses dados demonstravam, portanto, a quase completa ilegitimidade da instituição perante os jovens.

Em decorrência da insegurança que se estabeleceu nas vizinhanças controladas por traficantes e policiais corruptos, que difundiu em toda a cidade a desconfiança na instituição policial, formas de segurança privada se espalharam, e ainda se espalham, para proteger os que podem pagar ou que são obrigados a pagar, como acontece quando a segurança privada é ilegal. Este é o caso das "milícias", antes chamadas de grupos de extermínio. Elas surgiram nas áreas de ocupação mais recente da cidade, partindo de Jacarepaguá, onde se encontra a primeira favela dominada por um grupo de extermínio - Rio das Pedras -, povoada por migrantes nordestinos.

Nos resultados da pesquisa de vitimização 2005-2006, 25\% dos entrevistados admitiram ter formas de segurança privada bastante variadas: traficantes pagos ou não pagos, moradores pagos ou não pagos, vigilantes não uniformizados, empregados uniformizados de empresas de segurança, ou empregados não uniformizados. Muitas das empresas de segurança com funcionários uniformizados ou não nas áreas mais prósperas da cidade, como a Zona Sul, Tijuca, Barra da Tijuca e Jacarepaguá (AP 2 e AP 4 ) pertencem a policiais, assim como as "milícias" nas áreas pobres, como o centro, os subúrbios, a Zona Oeste e as favelas de Jacarepaguá (AP 1, AP 3, AP 5 e parte da AP 4), são dirigidas por ou mantêm estreita conexão com militares e ex-militares. A grande diferença está na relação do pessoal da segurança com os moradores. Nas áreas pobres, pela falta de acesso à justiça e a clandestinidade do empreendimento, mais facilmente os agentes da segurança privada tornam-se tiranos que impõem decisões extralegais ou ilegais aos moradores por conta do poder que advém das armas que afastam assaltantes e traficantes do local por eles vigiado.

Comparando as áreas da cidade pelo tipo de segurança privada, tivemos o seguinte quadro: ouvir tiros, ver trocas de tiros, pessoas agredindo outras pessoas, pessoas sendo mortas ou levadas à força, pessoas traficando ou usando drogas apresentavam proporções várias vezes superior (de três a cinco vezes maior) nas áreas em que os traficantes garantiam a segurança. $\mathrm{O}$ percentual de vizinhos, parentes ou amigos mortos também era maior nessas áreas. Nas favelas controladas por tráfico de drogas, mais do que o triplo dos entrevistados (45\%) afirmou ter visto venda de drogas em sua vizinhança por comparação aos entrevistados das favelas dominadas por "milícia" (14,9\%). O consumo de droga nas ruas também se apresentou aos moradores quase três vezes maior nas favelas dominadas por grupos de tráfico $(52,2 \%)$ do que nas favelas dominadas por "milícia" $(18,5 \%)$. Este resultado demonstra que a tolerância dos moradores, forçada ou não, e a convivência com o uso e o tráfico de drogas eram muito maiores, como seria de esperar, nas favelas dominadas por traficantes. Isso indica que, ao menos publicamente, um dos objetivos claros da "milícia" é coibir o uso e o tráfico de drogas, mas sem eliminá-los completamente.

Em relação a outros crimes temidos pela população, havia ainda mais disparidades entre as favelas. Nas dominadas por "milícias", 26,6\% dos entrevistados afirmaram ter visto assaltos na vizinhança, ao passo que nas dominadas por grupos de tráfico, $47 \%$ fizeram a mesma afirmação. Compreende-se: as "milícias", força paraestatal vinda dos grupos de extermínio, desde sempre foram criadas com o objetivo de impedir, por meios ilegais, a presença de suspeitos de praticarem assaltos; traficantes sempre se associaram a assaltantes para fazer capital de giro.

A atividade das "milícias" manifestava-se também no barulho de tiros ouvido pelos moradores das diferentes áreas, visto que as regiōes em que forneciam segurança, segundo os entrevistados, apresentavam tendências bem mais baixas na frequência de barulho de tiros ouvido. Em toda a cidade, sempre e frequentemente ouviam ruído de tiros $45 \%$ dos entrevistados, concentrados no Centro, na Zona Sul, na Tijuca e nos subúrbios (AP 1, AP 2 e AP 3), de urbanização mais antiga na cidade e onde havia muitas favelas dominadas por traficantes. Conflitos armados eram vistos por $13 \%$ dos entrevistados com maiores proporções no Centro, nos subúrbios e na Zona Oeste (AP 1, AP 3 e AP 5), onde há maior concentração de pobres, alem de, nas duas primeiras, mais favelas dominadas por traficantes. Na pesquisa domiciliar de vitimização feita apenas em favelas em 2007, 62\% dos entrevistados, naquelas dominadas por tráfico, ouviam 
sempre ou frequentemente barulho de tiros, contra $15 \%$ dos entrevistados nas favelas dominadas por "milícia". Raramente ou nunca ouviam barulho de tiros $34,2 \%$ dos entrevistados nas favelas dominadas por "milícia" e apenas $11,6 \%$, nas dominadas por tráfico; $42,5 \%$ dos residentes nas favelas dominadas por "milícia" afirmaram nunca ter ouvido barulho de tiro, enquanto $12,3 \%$ dos residentes em favelas controladas por traficantes afirmaram o mesmo. A proporção nestas últimas é, portanto, três vezes maior.

Não surpreende, pois, que moradores de favelas e áreas adjacentes a elas, que também têm proporção alta de pobres no Centro e nos subúrbios (AP 1 e AP 3), tenham recorrido cada vez mais a "milícias". Inicialmente, a mistura de respeito e medo, que resultou da presença da "polícia mineira" (ou grupo de extermínio) dentro da associação de moradores, guiava moradores a aceitar os milicianos. As normas impostas por aqueles que proibiam a venda e o uso de drogas, ou ladrões armados no local, passaram a ser vistas como algo "natural”, tornando desnecessárias as demonstrações conspícuas de força. Não havia armas à vista, nem atitudes visivelmente violentas, mesmo quando os milicianos estenderam seus negócios além da segurança para incluir outros bens e serviços, todos logo cobrados.

Posteriormente, a associação de moradores passou a fazer também a intermediação entre o poder público e a favela, pelo potencial eleitoral do local ou pela real possibilidade de eleger candidatos da favela. Os líderes da associação/polícia mineira, sob o discurso da necessidade de representação no governo como meio de sanar carências locais, começaram a candidatar-se a deputados estaduais ou vereadores. Em 2002 e 2003, por exemplo, a Associação dos moradores de Rio das Pedras, favela predominantemente habitada por migrantes nor-

Figura 1

Populaçáo Residente em Favelas segundo Domínio de Comandos de Tráfico ou Milícia

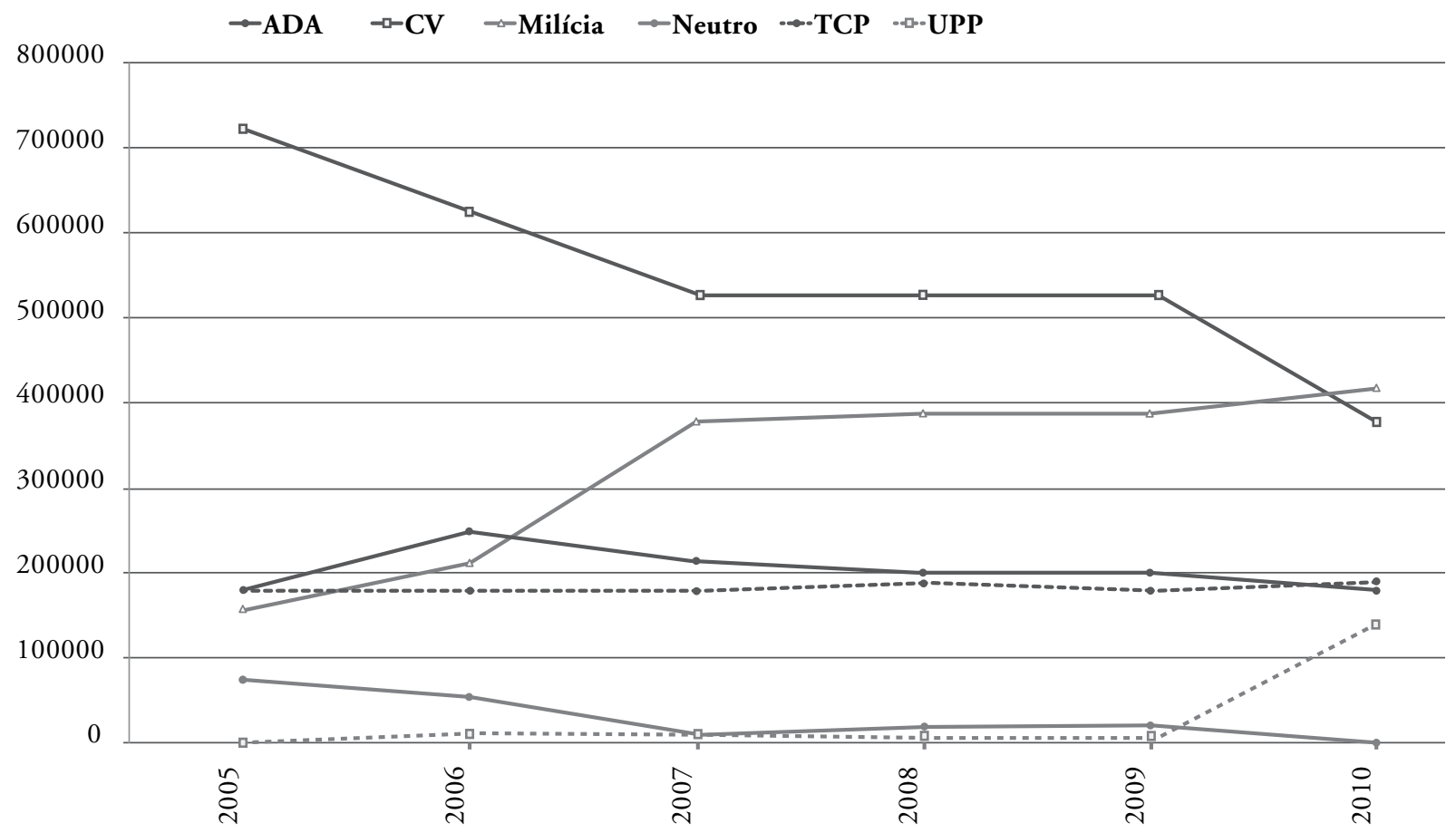

Fonte: “Levantamento Domínios em Favelas do Rio de Janeiro 2005-2011”, Nupevi/IMS/ERJ. 
destinos, promoveu campanha de regularização e transferência de títulos eleitorais e um líder local pertencente à "milícia" se elegeu vereador. A partir daí, outras favelas assim dominadas começaram a eleger representantes para o Legislativo da cidade e do estado (Zaluar e Conceição, 2007).

Mais recentemente, em áreas recém-povoadas e recém-conquistadas, nas quais se estabelecem os novos negócios e os compromissos eleitorais com políticos, as "milícias" dominam sem receber o apoio deles no cumprimento do código de conduta. Nessas favelas, componentes das novas "milícias" mantêm postura mais truculenta, exercendo seu poder com ostentação de armas e espancamentos seguidos ou ameaças aos moradores que se recusam a cumprir as ordens. Em algumas, a obrigação de votar no candidato indicado pelo poder armado passou a imperar. Não foi, portanto, apenas a preferência por um domínio mais eficaz na contenção da guerra entre comandos do tráfico e na garantia de não intervenção violenta da Polícia que provocou o crescimento irrefutável das áreas faveladas dominadas por milícias no Rio de Janeiro. Também o constrangimento, a invasão pura e simples das favelas, assim como a entrega delas pela associação de moradores, às vezes por meio de "venda" à organização, sem esquecer as injunções políticas de proteção dada por membros do Legislativo, contribuíram para este aumento.

O resultado da ação paradoxal da Polícia e da busca de segurança em outros grupos armados, como as milícias e os comandos de tráfico, está representado espacialmente nos mapas construídos a partir de um minucioso levantamento dos domínios instalados nas favelas da cidade entre 2005 e 2010.

\section{Levantamento de domínios nas favelas}

A Figura 2 mostra a população total das favelas segundo o domínio de grupos criminosos, neutras ou sob a atuação de UPPs ao longo dos últimos anos, de modo a compor o quadro resultante dos vários conflitos armados registrados na cidade em termos de domínio territorial de favelas

No ano de 2005 havia um claro predomínio do Comando Vermelho (CV) sobre as favelas do Rio de Janeiro, contando com cerca de 730 mil habitantes, quase a metade dos moradores de favelas do Rio de Janeiro, com cerca de 1.300 .000 habitantes. A partir de então, observa-se um decréscimo gradativo deste domínio, primeiramente com o avanço das milícias e mais recentemente com a instalação de UPPs. Ambas as iniciativas reduziram consideravelmente o domínio do $\mathrm{CV}$, mas pouco alteraram a territorialidade de outros grupos criminosos como ADA e TCP. Houve também uma diminuição do número de pessoas residentes em áreas neutras, das quais grande parte se encontra agora sob domínio de milícias, a organização que mais ganhou territórios na cidade.

As milícias, segundo dados de 2010, atuam em favelas com uma população total de cerca de 422 mil habitantes; o CV atua em áreas correspondentes a cerca de 377 mil habitantes; ADA e TCP atuam em áreas que possuem população de cerca de 180 mil habitantes. As UPPs, instaladas nas favelas maiores, cobrem áreas com população total de cerca de 142 mil habitantes, embora detenham apenas $7 \%$ das favelas da cidade. Hoje quase inexistem áreas neutras, ou seja, livres de domínios criminosos.

Analisando essa mudança de ocupação na cidade com base no mapa 1 (Figura 2), é possível verificar que, em 2005, as milícias estavam restritas à Zona Oeste (AP $4 \mathrm{e}$ AP 5), principalmente nos bairros de Jacarepaguá, Barra da Tijuca e Campo Grande, áreas de povoamento mais recente, com menor densidade populacional e com um percentual alto de migrantes nordestinos. No final do período, elas haviam se expandido para outros bairros da Zona Oeste, mas ainda distantes das favelas próximas à avenida Brasil. As únicas favelas que permaneceram sob o Comando Vermelho em 2008 estavam dentro do limite da Cidade de Deus (oficialmente um conjunto habitacional, não uma favela) e outra bem próxima. Cidade de Deus foi o cenário da primeira guerra de quadrilhas de traficantes no final dos anos de 1970 (Zaluar, 1985) e permaneceu a maior parte do tempo sob o domínio do CV até 2010. Na Zona Sul, região mais próspera, com famílias de renda alta e maior IDH (Cardoso, 2008), nenhuma favela foi ainda dominada pela milícia. No Centro e na Tijuca, bairros 
Figura 2

Distribuição Espacial das Favelas Dominadas por Facções do Tráfico, Milícias e UPP em 2006 e 2009

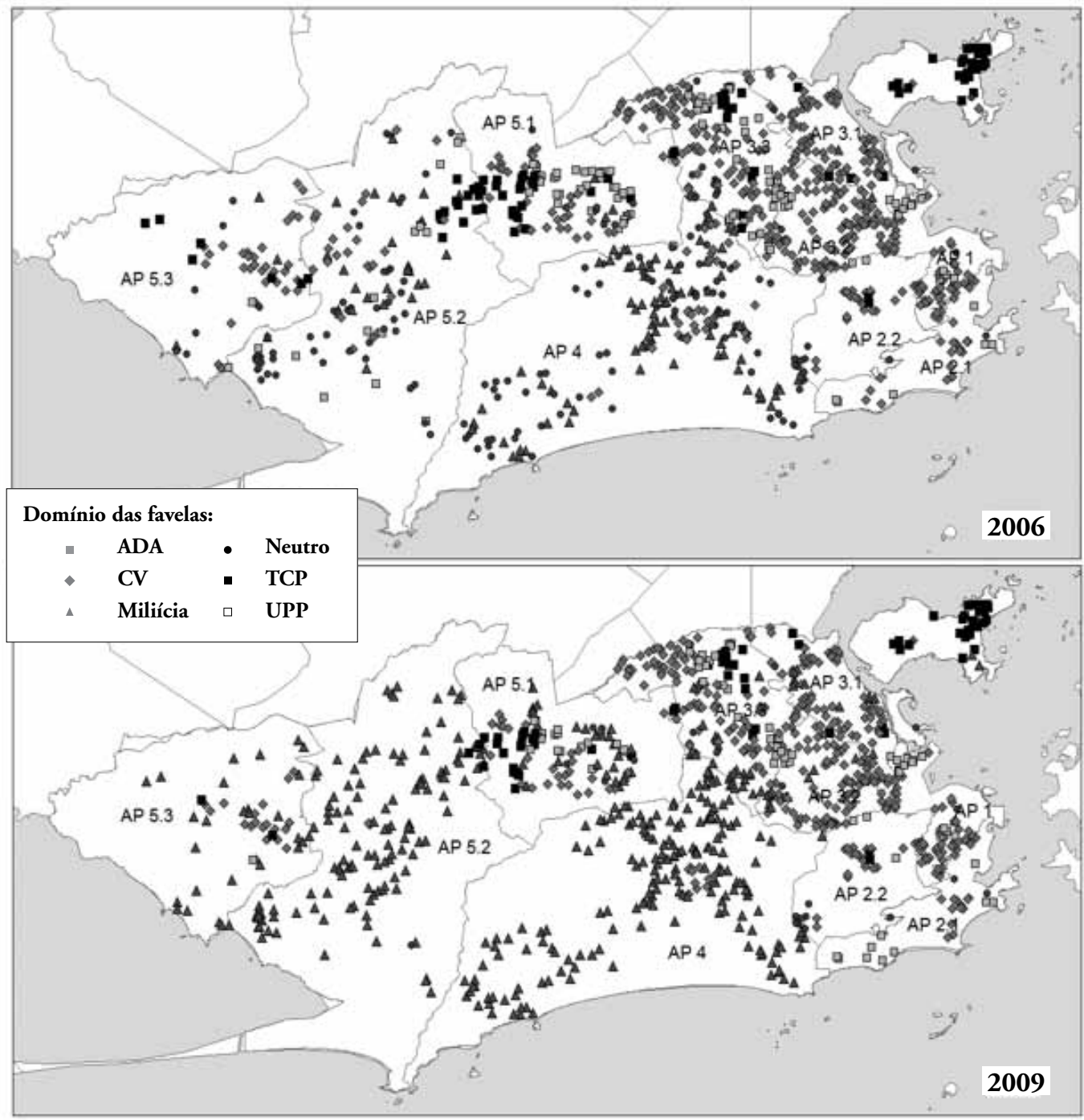

Fonte: “Levantamento domínios em favelas do Rio de Janeiro 2005-2010”, Nupevi/IMS/UERJ. Mapa elaborado pelos autores.

de classe média, também não houve presença de milícia, com a exceção da pequena favela da Baronesa, em Santa Teresa, apesar da importante presença de favelas em toda a região. Pela morfologia especial da cidade, são também as áreas em que o trânsito é mais difícil por conta das montanhas e do mar, ao contrário das áreas do subúrbio (AP 3), cortadas por grandes vias e mais próximas à Baía de Guanabara, que facilitam o escoamento rápido das mercadorias ilegais e a fuga de criminosos.

Os mapas da Figura 2 mostram que a expansão das milícias pela cidade, principalmente na Zona Oeste (AP 5) e nos subúrbios (AP 3), não mudou o domínio dos comandos de traficantes nas áreas mais próximas à Avenida Brasil, ao aeroporto internacional e ao Porto do Rio de Janeiro, que continuavam 


\section{Figura 3}

Mapa de Densidade de Homicídios (Kernel) segundo Local de Moradia da Vítima Ocorridos em 2006 e 2009

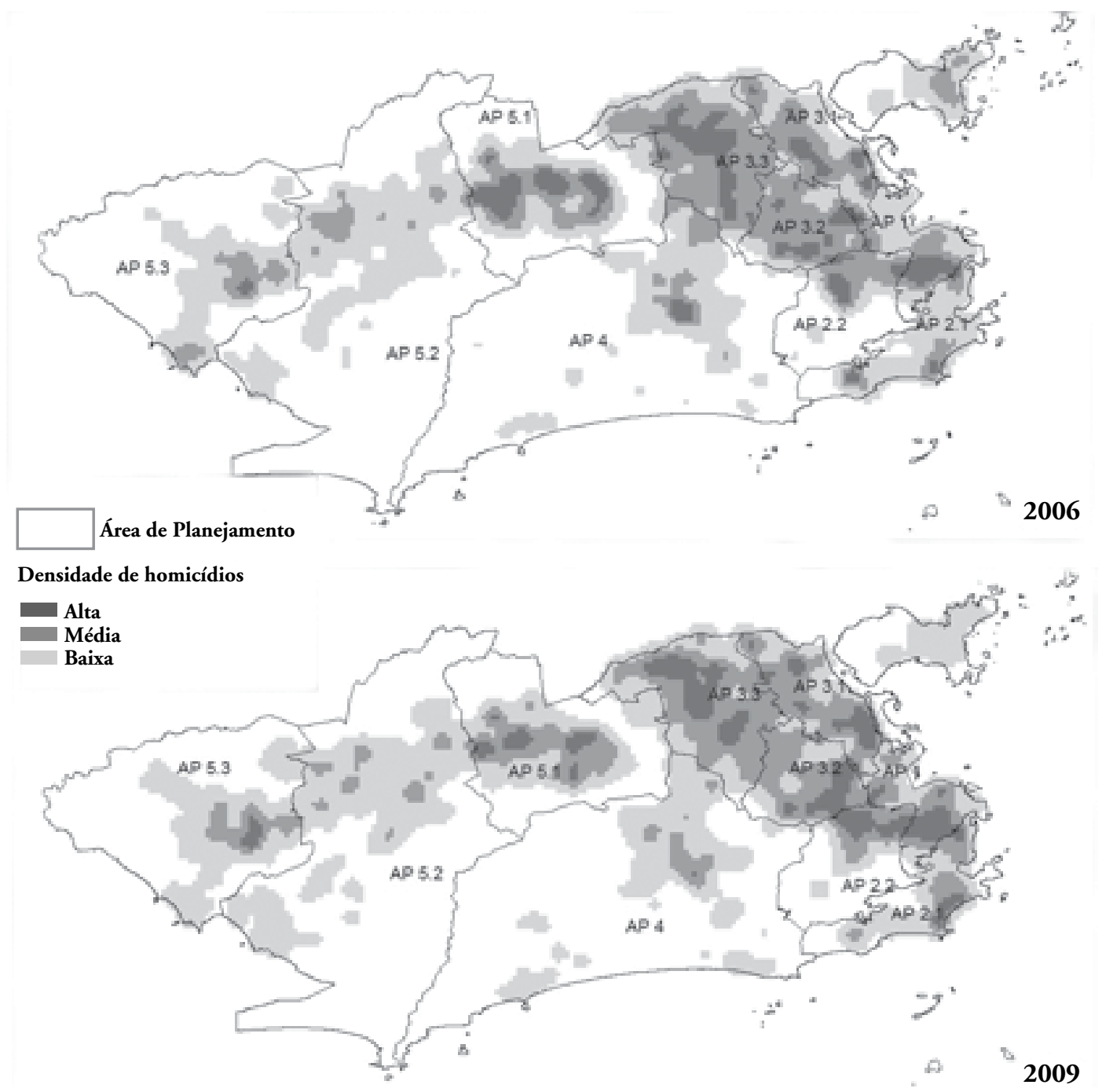

Fonte: Sistema de Informação sobre Mortalidade (SIM), Secretaria Municipal de Saúde do Rio de Janeiro. Mapa elaborado pelos autores.

sob seu controle. Havia poucas exceções nesse padrão. Uma era a Fazenda Botafogo, conjunto habitacional que fica do lado da Avenida Brasil, outra, a favela da Praia de Ramos: áreas industriais, com vários depósitos de carga e entrepostos de empresas comerciais perto da Avenida Brasil, o que as tornam alvo de repressão sobre a criminalidade circunstante.
O centro (AP 1) e os subúrbios (AP 3) eram os locais da maior concentração de homicídios, segundo os mapas 3 e 4 (Figura 3). Este padrão pode ser explicado pela concentração de recursos militares dos traficantes em áreas consideradas chave para o domínio de entrepostos de drogas, armas e muniçôes, devido a perdas e disputas ocorridas em 
outras regióes da cidade. Observa-se, no entanto, nos anos mais recentes, que a violência letal vem se concentrando ainda mais em alguns focos da cidade localizados nessas duas APs.

No ano de 2006, as áreas de maior densidade de homicídios, calculada pelo método de Kernel, formavam um corredor, acompanhando o trajeto da principal via de acesso à cidade (Avenida Brasil), que liga o Centro a todos os bairros do subúrbio e de lá à Zona Oeste. Observa-se um grande espalhamento pela cidade dessas áreas, com alguns focos na Zona Sul próximos à Rocinha e ao conjunto habitacional de Cidade de Deus na AP 4. Ao longo dos anos, culminando em 2009, as mortes por agressão estão mais concentradas em torno de três grandes áreas: o Complexo do Alemão, a Fazenda Botafogo, onde se encontra a favela do Acari, e a favela Vila Vintém, na Zona Oeste. As adjacências da Fazenda Botafogo presenciam até hoje uma luta pelo domínio territorial entre ADA, CV e "milícias”. Nas áreas em que a milícia consolidou o seu poder, nota-se igualmente a diminuição de homicídios, indicando a política de proibir o porte de armas entre os moradores e a ausência de conflitos entre os membros das várias milícias existentes na cidade. Em outras áreas tradicionalmente violentas, como a Tijuca e até mesmo a Cidade de Deus, fica menor, entre 2006 e 2009, a intensidade de mortes por agressão. Estas se tornam ainda mais esparsas na AP 4, com destaque para Cidade de Deus, onde foi instalada a segunda UPP em fevereiro de 2009, que passa de densidade alta para densidade média em 2009. Na Zona Sul, especialmente Copacabana, observa-se um adensamento de homicídios localizado entre Copacabana e Botafogo, que provavelmente corresponde a conflitos ocorridos na Ladeira dos Tabajaras em 2009, como verificado por trabalho de campo da equipe do projeto, conflitos ocorridos antes da instalação de UPP nas favelas de Copacabana.

A instalação de UPPs foi iniciada em novembro de 2008 na favela Santa Marta em Botafogo, logo seguida pela ocupação de Cidade de Deus, de favelas em Ipanema, Copacabana (AP 2.1) e na região da Tijuca (AP 2.2). Antes da ocupação por tropas do Exército em 2011, o Complexo do Alemão, no subúrbio, assim como a Rocinha na Zona Sul, eram bastióes de resistência armada e entrepostos respectivamente do $\mathrm{CV}$ e da ADA. Com a instalação da primeira UPP em Botafogo, houve uma fuga dos traficantes da favela Santa Marta e posterior invasão de outra favela próxima, a Ladeira dos Tabajaras, de onde os traficantes locais foram violentamente expulsos. Estes mudaram de comando e aliaram-se aos traficantes da Rocinha, de onde, juntos, tentaram retomar os pontos de venda localizados em Copacabana. Seguiram-se mais confrontos violentos entre traficantes que fizeram a polícia intervir. No total ocorreram, segundo a Agência Globo, 45 mortes em uma semana. Antes, confrontos na favela localizada no Leme e, mais tarde, na favela entre Copacabana e Ipanema fizeram dessa região uma das mais inseguras naquele ano, provocando manifestaçôes dos moradores de classe média e alta. A instalação da segunda UPP em Cidade de Deus não teve o mesmo efeito, visto que o conjunto habitacional se localiza em área quase que totalmente dominada por milícias, e os traficantes aprenderam a lição de que invadir favela inimiga traria como consequência uma operação policial imediata. Em 2009 foram instaladas UPPs nas favelas de Copacabana e Ipanema, e ali também não houve invasão de quaisquer favelas próximas.

\section{Levantamento de favelas dominadas}

No Rio de Janeiro, a distribuição geográfica de mortes por agressão, a percepção de crimes cometidos com uso de armas e os domínios obedecem a determinantes ecológicos em áreas delimitadas da cidade. Nas várias pesquisas de campo realizadas pela equipe do Nupevi, sempre foi assinalada, desde 1980, a facilidade e a quantidade de armas disponíveis para os jovens moradores das favelas consideradas perigosas. As duas pesquisas domiciliares de vitimização revelam em que áreas estão concentradas as favelas dominadas por traficantes no Centro e nos subúrbios (AP 1 e AP 3), embora elas sejam encontradas também em todas as regióes. Os abusos no uso da força policial, registrados nas duas primeiras pesquisas, são também muito mais recorrentes ali.

Um conjunto de características destacam tais áreas quanto à exposição a riscos de morte pre- 
matura por arma de fogo. Ali vivem os habitantes mais antigos, em geral negros, que povoaram a área central e os subúrbios da cidade há mais de um século. É nelas que a grande circulação de armas de fogo e, portanto, sua fácil obtenção, estimula o etos guerreiro, que se traduz em conflitos armados cujo final é inevitavelmente trágico (Szwarcwald e Leal, 1997). Áreas controladas por traficantes, onde, para manter o domínio do território, cobrar dívidas, afastar concorrentes e amedrontar possíveis testemunhas, é corriqueiro o uso da armas de fogo, mais facilmente obtidas pela proximidade de portos, aeroportos e dos mais importantes depósitos de armamentos das Forças Armadas. O tráfico de drogas tornou-se militarizado em consequência de furtos frequentes nesses depósitos (Dowdney, 2004, 2008; Zaluar, 2004). O mapeamento dos domínios revelou que, no que se refere à disputa com as milícias, a localização geográfica nos permite entender por que nessas duas APs havia e ainda persiste mais resistência dos traficantes em entregar seu domínio.

A pesquisa etnográfica feita em 2007 pela equipe do Nupevi permite afirmar que por se autoidentificar como mantenedora da ordem, a "milícia” apresenta procedimentos aparentemente percebidos como menos agressivos do que aqueles utilizados pelos traficantes de drogas. Além disso, a origem dos milicianos dentro dos próprios quadros policiais contribui para o estabelecimento da ordem no local. A presença desses grupos paraestatais -em sua maioria, policiais civis, militares e bombeiros militares, além de guardas penitenciários, ativos, reformados ou aposentados - garante uma participação diferenciada dos agentes públicos de segurança em favelas, isto é, nestas áreas as incursões policiais, quando ocorrem, costumam ser pacíficas.

Inicialmente, o sentimento de respeito e medo derivado da presença da "polícia mineira" (ou grupo de extermínio) dentro da associação de moradores, levou-os a aceitar os milicianos. As normas impostas por estes, que proibiam a venda e o uso de drogas ou ladróes armados no local, eram vistas como "naturais", tornando desnecessárias as demonstrações conspícuas de força, mesmo quando eles estenderam seus negócios além da segurança.

Posteriormente, a associação de moradores passou a fazer também a intermediação entre o poder público e a favela, pela real possibilidade de eleger candidatos da favela como meio de sanar carências locais. Em 2002, a Associação dos Moradores de Rio das Pedras, favela predominantemente habitada por migrantes nordestinos, promoveu campanha de regularização e transferência de títulos eleitorais, e um líder local pertencente à "milícia" se elegeu vereador. A partir daí, outras favelas assim dominadas começaram a eleger representantes para o Legislativo da cidade e do estado (Zaluar e Conceição, 2007).

Mais recentemente, em áreas recém-povoadas e recém-conquistadas, nas quais as milícias estabelecem de antemão os novos negócios e os compromissos eleitorais com políticos, elas dominam sem receber o apoio deles no cumprimento do código de conduta. Nessas favelas, componentes das novas "milícias" mantêm postura mais truculenta, exercendo seu poder com ostentação de armas e espancamentos seguidos ou ameaças aos moradores que se recusam a cumprir as ordens.

Enquanto os traficantes sofrem os efeitos de confrontos armados constantes com as polícias, os milicianos contam com a indiferença dos chefes das corporações, que só os atacam quando ordens superiores ordenam. Mas é inegável que o controle e a exploração para fins lucrativos de um território, sem o amparo da lei, podem desembocar no uso abusivo da força por parte das "milícias".

Para interpretar tais fatos, o material etnográfico recolhido em pesquisa feita com ex-traficantes em 2008 revela uma pista importante. Vários entrevistados mencionaram que as transações de armas e drogas entre vendedores das favelas cariocas e os fornecedores vindos de outros estados são realizadas, para não despertar suspeitas, em postos de gasolina, motéis e outros pontos ao longo da avenida Brasil. Matérias publicadas nos jornais do Rio de Janeiro, corroborando o relato de alguns entrevistados, revelaram transações e apreensões da mesma natureza no aeroporto internacional (AP 3) e no porto (AP 1). Essas atividades demonstram a extensão dos domínios das milícias para além dos territórios das favelas e a importância estratégica destas vias de circulação na geopolítica de drogas e armas na cidade.

Contra a teoria da escolha racional está, portanto, o paradoxo de que a própria existência de mais de um comando suscita extrema violência no tráfico de dro- 
gas do varejo, devido à disputa pelo domínio sobre os territórios onde se instalam os pontos de venda e os paióis de armas e muniçōes (Dowdney, 2004, 2008; Zaluar, 1994, 2004). Ora, localmente os traficantes fomentam práticas subterrâneas e violentas de resolução de conflitos, com luta perene pelo controle do comércio e pelas posições de poder. Isso torna os custos das operaçôes cada vez mais onerosos, visto que é preciso comprar mais e mais armas de combate e aumentar o contingente de corrupção entre os agentes da lei. Por isso mesmo, o domínio de favelas mais próximas de locais onde ocorrem efetivamente as transaçóes portos, aeroportos, vias importantes de circulação (avenidas Brasil, Presidente Dutra e Washington Luís), que ligam a cidade ao interior e a outros estados do Brasil - vem se constituindo numa estratégia para diminuir os gastos com transporte e segurança das mercadorias, compensando as despesas geradas por conflitos armados entre os comandos, e entre estes e a polícia.

De todo modo, os procedimentos aqui adotados demonstram a necessidade de integrar esforços de vários setores do governo para mapear riscos. Os mapas permitiram visualizar a concentração de homicídios nas áreas de conflito por locais estratégicos da geopolítica de drogas e armas na cidade. Estas áreas necessitam de urgentes intervenções no controle do fluxo de armas e munições, bem como de programas de prevenção da violência entre jovens vulneráveis, que concorram para diminuir os fatores de risco de morte prematura, oferecendo mais proteção a eles e seus vizinhos.

\section{Notas}

1 Para o relatório completo, ver Zaluar et al., 2007 no site do Nupevi: <www.ims.uerj.br/nupevi>.

2 Nesta pesquisa, os que portam armas constituíram 20\% da amostra de adolescentes negros entre 12 e 15 anos entrevistados. Os jovens mencionaram 19 vezes, mais do que os que não portam armas, que têm colegas também portadores de armas de fogo (Zaluar et al., 2007).

3 Depois de entrevistar quatrocentos jovens nas vizinhanças mais perigosas de Nova York, Fagen descobriu que a violência se expandiu entre 1985 e 1995 pelo contágio de ideias e posturas entre colegas e vizinhos.

\section{BIBLIOGRAFIA}

BAILEY, T.C. \& GATRELL, A. C. (1995), Interactive spatial analysis. Essex, Longman.

BEATO F., Claudio C. (1998), "Determinantes da criminalidade em Minas Gerais". Revista Brasileira de Ciências Sociais, 13 (37): 74-87.

BOURDIEU, Pierre. (1972), Esquisse d'une théorie de la pratique. Geneva, Droz.

BOURDIEU, Pierre \& WACQUANT, Löic. (1992), An invitation to reflexive sociology. Chicago, The University of Chicago Press.

BOURGOIS, Pierre. (1996), In search of respect, selling crack in el barrio. Cambridge/Nova York, Cambridge University Press.

BURAWOY, Michael. (1998), "The extended case method". Sociological Theory, 16 (1): 4-33. . (2000), "Introduction: reaching for the global", in M. Buroway et al. (eds.), Global ethnography: forces, connections, and imaginations in a postmodern world, Berkeley, University of California Press, pp. 1-40.

CARDOSO, Adalberto A. (2008), Cidade do Rio de Janeiro na PNAD: condiçôes de vida, educação, renda e ocupação entre 2001 e 2006. Rio de Janeiro, Instituto Municipal de Urbanismo Pereira Passos.

CECCHETTO, Fátima. (2004), Violências e estilos de masculinidade no Rio de Janeiro. Rio de Janeiro, FGV.

CONNEL, R. W. (1987), Gender and power. Cambridge, Polity Press. . (2004), Crianças no tráfico. Rio de Janeiro, 7 Letras.

. (2008), Neither war nor peace. Rio de Janeiro, Viva Rio/Coav/Iansa.

ELIAS, Norbert \& DUNNING, E. (1993), Quest for excitement, sport and leisure in the civilizing process. Blackwell, Paperback Oxford.

FAGAN, J. (2005), "Guns and youth violence". Children, Youth, and Gun Violence, 12 (2). Disponível em <www.futureofchildren.org $>$.

GEFFRAY, C. (2002), "Social, economic and political impacts of drug trafficking in the state of Rondônia”, in C. Geffray, G. Fabre e M. Schiray (eds.), Globalization, drugs and criminalization, Paris, UNODCCP, vol. 1. 
GLUCKMAN, Max. (1961), "Ethnographic data in British social anthropology". The Sociological Review, 9 (1): 5-17.

HOLLAND, Sally \& COURFIELD, Jonathan B. (2000), "Managing marginalised masculinities: men and probation". Journal of Gender Studies, 9 (2): 199-211.

IYER, S. \& MONTEIRO, M. F. G. (2004), “The risk of child and adolescent mortality among vulnerable populations". Journal of Biosocial Science, 36 (5): 523-546.

LUPPO, S. (2002), História da máfia. São Paulo, Editora da Unesp.

KALDOR, M. (1999), New and old wars. Stanford, Stanford University Press.

MONTEIRO, Rodrigo A. (2009), Prevenção da violência: o caso dos projetos esportivos no subuirbio carioca. Rio de Janeiro, tese de doutorado, Instituto de Medicina Social, Universidade do Estado do Rio de Janeiro.

NEWMAN, G. \& CLARKE, R. \& SHOHAM, S. G. (1997), Rational choice and situational crime prevention. Ashgate, Darmouth Publishing Company.

MYERS, G. P.; MCGRADY, G. A.; MARROW, C. \& MUELLER, C. W. (1997), "Weapon carrying among black adolescents: a social network perspective". American Journal of Public Health. 87 (6):1038-1040.

PEREIRA, Luis Fernando A. (2008), Meninos e lobos, trajetórias de saida do tráfico na cidade do Rio de Janeiro. Rio de Janeiro, tese de doutorado, Instituto de Medicina Social, Universidade do Estado do Rio de Janeiro.

PINA, M. F. (1998), "Potencialidades dos sistemas de informaçōes na área da saúde", in A. Najar e E. Marques (eds.), Saúde e espaço: estudos metodológicos e técnicas de análise, Rio de Janeiro, Fiocruz, pp. 125-133.

RESNICK, M.; IRELAND, M. \& BOROWSKY, I. (2004), "Youth violence perpetration: What protects? What predicts? Findings from the national longitudinal study of adolescent health". Journal of Adolescent Health, 35: 424E1-424 E10.

ROJAS, LI; SANTOS, S. M. \& BARCELLOS, C. (2005), "Diferenciación espacial de la violencia en America Latina", in Maria Cecília de Souza M. (org.), Críticas e atuantes: ciências sociais e humanas em saúde na América Latina. 1. ed. Rio de Janeiro, Fiocruz, vol. 1, pp. 665-686.

SANER, H. L. \& ELLIKSON, P. L. (1996) "Concurrent risk factors for adolescence violence", Journal of Adolescent Health, 19 (2): 94-103.

SWARTZMAN, Simon \& COSSÍO, M. B. (2006), "Juventude, educação e emprego no Brasil". Cadernos Adenauer - Geração Futuro, VII (2): 51-65.

SZWARCWALD, C. L. \& LEAL, M. C. (1997), "Sobrevivência ameaçada dos jovens brasileiros: a dimensão da mortalidade por armas de fogo", in CNPD, Jovens acontecendo na trilha das políticas públicas, Brasília, CNPD, vol. 1.

VINE, M. F; DEGNAN, D. \& HANCHETTE, C. (1997), "Geographic information Systems: their use in environmental epidemiologic research". Environ Health Perspect, 105(6):598-605.

ZALUAR, Alba. (1985), A máquina e a revolta. São Paulo, Brasiliense.

(1998). PARA NÃO DIZER QUE NÃO FALEI DE SAMBA. SCHWARTZ, L (ed.), História da Vida Privada no Brasil vol.IV, São Paulo: Cia das Letras. 245-318. (1994), Condomínio do diabo. Rio de Janeiro, Editora da UFRJ/Revan. . (2001), "Violence in Rio de Janeiro: styles of leisure, drug use, and trafficking". Social Science Journal, LIII (3): 369-379. (2004), Integração perversa: pobreza e tráfico de drogas. Rio de Janeiro, FGV.

ZALUAR ALBA et al. (2007), "Pesquisa domiciliar de vitimização do Rio de Janeiro". Relatório Técnico, Rio de Janeiro, Núcleo de Pesquisa das Violências/Instituto de Medicina Social/Uerj. Disponível em <www.ims.uerj.br/nupevi> .

ZALUAR, Alba \& CONCEIÇÃO, Isabel Siqueira. (2007), "Favelas sob o controle das milícias no Rio de Janeiro: que paz?". São Paulo em Perspectiva, 21 (2): 89-101. 


\section{MORTES PREMATURAS E CONFLITO ARMADO PELO DOMÍNIO DAS FAVELAS NO RIO DE JANEIRO}

\section{Alba Zaluar e Christovam Barcellos}

Palavras-chave: Conflito armado; Tráfico de drogas; Distribuição dos delitos; Favela; Violência.

$\mathrm{O}$ artigo se propõe a ir além do uso de variáveis socioeconômicas e individuais agregadas relativas à pobreza, para incluir fatores relacionados com o espaço urbano, hoje parte da explicação sociológica do crime. A análise ecológica das distribuiçóes dos delitos busca a compreensão da natureza complexa da violência para identificar fatores que influenciam o comportamento, aumentando ou diminuindo o risco de cometer ou de ser vítima de violência nas mesmas condições socioeconômicas. Como muitos dos indicadores são dificilmente mensuráveis, as respostas a essas questôes tornam a pesquisa etnográfica imprescindível, com a necessária substituição de alguns conceitos para incluir as práticas sociais interiorizadas (etos) que permitem a articulação entre o subjetivo e o objetivo, o micro e o macro. Para acompanhar os complexos processos que provocam e consolidam tais práticas sociais, a pesquisa foi feita segundo o método dos casos desdobrados, que permite vincular o local a outras esferas da vida social em abordagem histórica com pluralidade de fontes de dados. O mapeamento dos diferentes domínios nas favelas (milícias, diversas facçôes de tráfico e neutras) permitiu identificar áreas de conflito, que se concentram próximas a rodovias, portos e aeroportos, o que evidencia uma configuração geopolítica dos conflitos armados pelos territórios do tráfico. Este resultado é ressaltado pela alta incidência de homicídios registrados nos bancos de dados oficiais e nas percepções apresentadas nas pesquisas de vitimização.

\section{PREMATURE DEATHS AND TURF WAR TO DOMINATE FAVELAS IN RIO DE JANEIRO}

\section{Alba Zaluar and Christovam Barcelos}

Keywords: Turf war; Drug trafficking; Crime distribution; Favela; Local; Violence.

This article intends to go beyond the use of individual and aggregate socioeconomic variables related to poverty, incorporating factors referred to the urban space dimension, which is considered today part of the sociological explanation of crime. The ecological analysis of criminal offenses seeks to understand the complex nature of violence in order to identify factors influencing behavior, increasing or decreasing the risk of perpetrating violence or being victimized by it in the same or similar socioeconomic conditions. Since several indicators are barely measurable, ethnographic research becomes indispensable, what implies the necessary replacement of some concepts, in order to include embodied social practices (ethos) allowing for an articulation between the objective and the subjective, the macro and the micro. Aiming at tracing the complex processes that promote and consolidate such social practices, the research employed the method of extended cases, what made possible to link the local to other spheres of social life in an historical approach involving a plurality of sources. The mapping out of the different dominions in the favelas (militias, factions of the drug trafficking, and other groups) allowed the identification of conflict areas concentrated in the proximity of major highways, ports and airports, what shows a geopolitical configuration of the armed conflicts along the drug trafficking territories. Such outcome is highlighted by the high rate of homicides reported in official databases and in the perceptions of victimization revealed by surveys.

\section{MORTS PRÉMATURÉES ET CONFLIT ARMÉ POUR LE CONTRÔLE DES FAVELAS À RIO DE JANEIRO.}

\section{Alba Zaluar et Christovam Barcellos}

Mots-clés: Conflit armé; Trafic de drogue; Localisation des délits; Favela; Violence.

L'article propose un abordage qui va audelà de l'emploi de variables socioéconomiques et individuelles agrégées, relatives à la pauvreté. Il inclue des facteurs liés à l'espace urbain, qui aujourd'hui fait partie de l'explication sociologique de la criminalité. L'analyse écologique de la localisation des délits cherche à comprendre la nature complexe de la violence dans le but d'identifier les éléments qui influencent le comportement, en augmentant ou en diminuant le risque de commettre ou d'être victime de la violence dans les mêmes conditions socioéconomiques. Comme plusieurs des indicateurs sont difficilement mensurables, les réponses à ces questions rendent indispensable l'étude ethnographique, en remplaçant certains concepts pour inclure les pratiques sociales intériorisées (ethos) qui permettent l'articulation entre le subjectif et l'objectif, entre le micro et le macro. Pour accompagner les processus complexes qui provoquent et qui consolident de telles pratiques sociales, la recherche a été développée suivant la méthode des cas étendus, qui permet d'associer le local à d'autres sphères de la vie sociale dans l'approche historique avec une pluralité de sources de données. L'identification géographique des différents domaines dans les favelas (milices, diverses factions $\mathrm{du}$ trafic de drogue et neutres) a permis d'identifier les zones de conflit, qui se concentrent à proximité des routes, des ports et des aéroports, ce qui met en évidence une configuration géopolitique des conflits armés par les territoires du trafic. Ce résultat est mis en avant par la haute incidence d'homicides inscrits sur les banques de données officielles et dans les perceptions présentées dans les recherches de victimisation. 